\title{
Factors Affecting Continued Use of Online Health Information Seeking Behaviour Among Parents in Developing Countries
}

\author{
Mira Kartiwi', Teddy Surya Gunawan², Jamaluddin Ab Rahman ${ }^{3}$ \\ ${ }^{1}$ Department of Information Systems, Faculty of Information and Communication Technology, \\ International Islamic University Malaysia, Malaysia \\ ${ }^{2}$ Department of Electrical and Computer Engineering, Faculty of Engineering, \\ International Islamic University Malaysia, Malaysia \\ ${ }^{3}$ Department of Community Medicine, Faculty of Medicine, International Islamic University Malaysia, Malaysia
}

Article History: Received: 10 November 2020; Revised: 12 January 2021; Accepted: 27January 2021;

Published online: 05April 2021

\begin{abstract}
The advancement of technology has changed how parents engage in health information seeking activities through the Internet. Such trends not only shown in developed countries but also most of developing economies as the growth of population access to Internet have been steadily increased in the past ten years. Despite the growing penetration rate, little is known on the extent the Internet is being used by parents to obtain health-related information to improve the wellbeing of their children in developing countries. Five hundred and nineteen responses were collected from parents in selected areas of Klang Valley region in Malaysia. The collected data were analysed by partial least square method of structural equation modelling. The results indicated a positive relationship between information satisfaction and online health information seeking continued use. The moderating role of household income and education are confirmed. The research implications of our results would help medical practitioners and policymaker to design the appropriate supports and awareness programs for parents on the risk and benefits of using online health information.
\end{abstract}

Keywords:Information seeking, health information, online behaviour, developing countries

\section{Introduction}

Recent report shows that the penetration of Internet worldwide had achieved 7.7 billion, with a coverage rate of 58.8\% [1]. More and more countries in both developed and developing countries are accelerating their effort to reap the benefits of the digital era and to ensure the sustainable growth of the country, and wellbeing of the citizens. Not only at national levels, with the rapid growth of technology, many individuals are turning to the Internet to get information about health and health care to improve his/her wellbeing $[2,3]$.

In addition, the development of the Internet as a source of health information had also triggered studies to understand the determinants of information satisfaction $[4,5]$ and continuance intention to search for health information online [6].

While there are growing numbers of documented research on the determinants of online health information seeking in developed countries, limited studies had been carried out in developing countries, especially to examine how parents use online health information to improve the wellbeing of their children. Hence, this study aimed to assess the online health information-seeking behaviours among parents and the influence of parents' information satisfaction on continuance intention. The authors also examined issues such as perceived barriers, perceived benefits and perceived self-efficacy, and how they would or would not influence the satisfaction of the health information retrieved from the online sources. We believe that the findings of our study will help future efforts in supporting primary care practitioners in their daily care of patients, as well as the governments to create appropriate interventions to improve the wellbeing of the citizens.

\section{Literature Review}

\subsection{Online Health Information Seeking Behaviour}

A number of earlier studies have examined the online information-seeking behaviours. Among the common findings were the used of internet as a medium to search for alternative health information [3], given convenience and accessibility of finding more detailed information of certain illness to support decision making on health treatment or self-management among individuals with chronic health conditions [2, 7, 21, 22].

Research also shows that parents are using the Internet to search for health information to improve the wellbeing of their children. For example, a recent study by Nicholl et al. [8] who attempted to explore parents' general Internet usage patterns on online health information seeking in Ireland. Their study shows how parents 
with children with rare conditions to utilise the Internet search engines and social media as a platform to seek information that helps them to improve their child's health condition. Such approached was reported to have helped the parents to deal with stress and anxiety that surrounds caregiving for their children and at the same time, enhancing their knowledge and understanding of their child's condition.

Similar findings were also reported from the earlier studies carried out in US [9, 23], Australia [10],Korea [25] and Switzerland [11]. These studied reported that online resources have proven to positively influence parents' decision making, care, and management of their child's condition. However, the research laso reported on the mixed responses that the parents received from the health care providers when they share the information they gained on the Internet. Majority of the health care professionals having no interest at all in the information while others show some interest but not enough to deem the gained information is important [9].

Moon et al. [12] studied the parental perceptions of the advantages and disadvantages of the online search through the Internet and social media as sources of parenting and health information regarding their children. The results of this qualitative study highlight that among the reasons why parents refer to the Internet for parenting and health information were for quick crowdsourcing for viewpoints gathering, anonymity of the web, the convenience of the internet as compared to reaching out to a health care provider, the Internet's large information base and updated information. The study also reported how parents, especially mothers, cautioned each other about the information sources on the web and warn to only consider information from reputable websites.

\subsection{Information Satisfaction and Continuance Usage Intention}

Previous research has identified a number of demographic variables that influence the health information seeking behaviour among Internet users. Among others is the study by Jacobs et al. [3] and Pluye et al. [15]. They identified the significant influence of education and self-efficacy on the use of online materials to access health information. Hiebert et al. [16] and Manierre [24] reported that health information seeking behaviour significantly differently between male and female.

\subsection{Demographic Factors Affecting Online Health Information Seeking Behaviour}

A number of past research in the domain of information systems that shows how information satisfaction had been identified as key predictor to continuance intention [13]. Bhattacherjee [14] constructed a model, called the Expectation Confirmation Model (ECM), which aimed to predict users' continuing behaviour in an information system to explore the factors affecting brand community user's continuance intentions. The model had been adopted in a number of studies, with the finding that the perceived usefulness - or some termed it as perceived benefits - of system users have positive impact on the satisfaction and continuance intention. It is believe that the satisfaction and continuance intention constructs proposed by Bhattacherjee [14] proposed as part of the ECM were found to be appropriate even within the e-health and information seeking behaviour context. Therefore, the two constructs are important to be included in this study.

\subsection{Proposed Research Model and Hypotheses}

The literature has demonstrated the potential relationship between several constructs included in this study, i.e. perceived barriers, perceived benefits, perceived self-efficacy, e-health information satisfaction, and continuance intention.

Hence it is hypothesised that:

H1:Perceived Barriers has a negative relationship on the satisfaction of the health information retrieved from the online search

H2:Perceived Benefits has a positive relationship on the satisfaction of the health information retrieved from the online search

H3:Perceived Self-Efficacy has a positive relationship on the satisfaction of the health information retrieved from the online search

H4:Information Satisfaction has a positive relationship towards the continuance intention to search for health information online. 


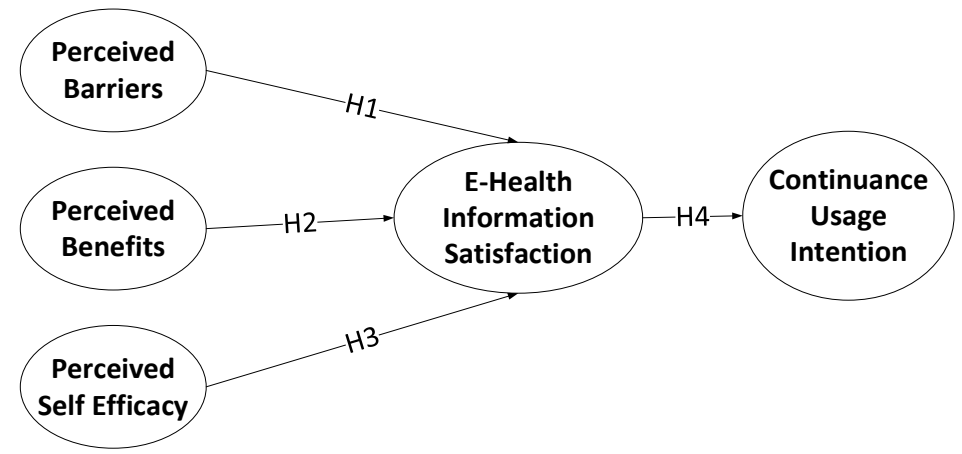

Figure 1. Proposed Research Model

\section{Methodology}

\subsection{Demographic Information}

In this research, a survey-based quantitative method was designed to conduct this study. Based on the latest Malaysian Communications and Multimedia Commission [17] report, the penetration of internet in Malaysia is high, particularly in the urban area. Hence Klang Valley region is selected in this study. The data were collected from 519 parents as detailed in Table 1.

Table 1. Summary of Demographic Variables of the Respondents

\section{Demographic}

\begin{tabular}{|c|c|c|}
\hline & & (P) \\
\hline Age & $\begin{array}{r}20-30 \\
31-40 \\
41-50 \\
51-60 \\
>=61\end{array}$ & $\begin{array}{ll}118 & (22.7 \%) \\
202 & (38.9 \%) \\
138 & (26.6 \%) \\
47 & (9.1 \%) \\
13 & (2.5 \%)\end{array}$ \\
\hline Gender & $\begin{array}{r}\text { Male } \\
\text { Female }\end{array}$ & $\begin{array}{ll}245 & (47.2 \%) \\
274 & (52.8 \%)\end{array}$ \\
\hline Education & $\begin{array}{r}\text { High School } \\
\text { Diploma } \\
\text { Bachelor } \\
\text { Master } \\
\text { Others }\end{array}$ & $\begin{array}{l}133(25.6 \%) \\
86(16.6 \%) \\
193(37.2 \%) \\
54(10.4 \%) \\
49(9.4 \%)\end{array}$ \\
\hline $\begin{array}{r}\text { Household } \\
\text { Income }\end{array}$ & $\begin{array}{r}<\mathrm{RM} 1000 \\
\text { RM1000- } \\
2499 \\
\text { RM } 2500- \\
5499 \\
\text { RM } 5000- \\
7999 \\
>\text { RM } 8000\end{array}$ & $\begin{aligned} 30 & (5.8 \%) \\
107 & (20.6 \%) \\
174 & (33.5 \%) \\
103 & (19.8 \%) \\
105 & (20.2 \%)\end{aligned}$ \\
\hline
\end{tabular}

Total

(Percentage)
As can be seen in Table 1, the majority respondents participated in this study were young mothers or fathers aged under 40 years old. Around $47 \%$ of the respondents had at least a bachelor's degree, with $16.6 \%$ having graduate diploma and $25.6 \%$ were high school graduates.Concerning household income, the government of Malaysia categorised household income into three categories; Top 20\% (T20), Middle 40\% (M40), and Bottom $40 \%$ (B40). However, in this study, we adopted the income discretization of the previous national survey that classify household with more than 8000 as T20, the M40 category as the household with income between RM2500-7999, low income (B40) is any household that earn less than RM2500 monthly. As indicated in Table 1 , majority of the respondents in this study were categorized under medium income (53.3\% - M40), while $26.4 \%$ were in low income categories, and the remaining of the respondents were in top income category (T20). Tables and Figures are presented center, as shown in Table 1 and Figure 1, and cited in the manuscript before appeared. 


\subsection{Data analysis using the PLS approach}

Before the data were analysed, it was necessary to assess its properties. The proposed research model was tested using SmartPLS 3.0 software by applying Partial Least Squares (PLS) algorithm. PLS is a variance-based structural equation modeling technique where it facilitates the researcher to focus on the prediction of the dependent variable through assessment of the structural paths [18]. The technique also facilitates the complex analysis in terms of the number of relationships and the levels of dimensionality. In this research, the factor analysis was also applied to confirm the dimensionality of the first order dimensions, which then followed by operationalising the multidimensional constructs through the implementation of a two-stage approach [19].

\section{Results and Discussions}

The aim of this study is to understand how the perceived barriers, perceived benefits and perceived selfefficacy's influence on information satisfaction and subsequently on continuance intention to seek health information online. The proposed model proposed in this study was evaluated by examining the t-statistics, structural paths, and path significances. The results of PLS analysis were generated by running the model using a bootstrap resampling routine with 519 cases and 5000 samples. Given this is a nonparametric method to assess the significance level of PLS estimates, the sub-samples were generated by randomly choosing a case from the data set [20].

Table 2 highlights the results of the path analysis of the proposed model using PLS. As can be seen, consistent with our H1, perceived barriers were negatively influence the online health information satisfaction. The parent who believes that searching health information online is time consuming, difficult and having too much information is a disadvantage; would feel a greater dissatisfaction on the information retrieved. In addition, consistent with $\mathrm{H} 2$ and $\mathrm{H} 3$, the perceived benefits and perceived self-efficacy are positively predicted the satisfaction of the online information retrieved by parents. In other words, the parents who found searching health information online would give value add in improving the wellbeing of the children; were more likely to higher satisfaction on the health information online.

Table 3 shows the moderating effects on the proposed model. Interestingly, out of 3 moderating variables were tested (gender, level of education and household income), only 2 variables emerged to moderately influence a few paths in the model. The household income was negatively moderating effect on the link between perceived self-efficacy and online health information satisfaction, with a path coefficient of 0.07 , and a t-value of 1.894.This implied that when an individual has a higher income, the positive relationship between perceived self-efficacy and information satisfaction would diminish. Figure 2 summarises the final model with the moderating variables.

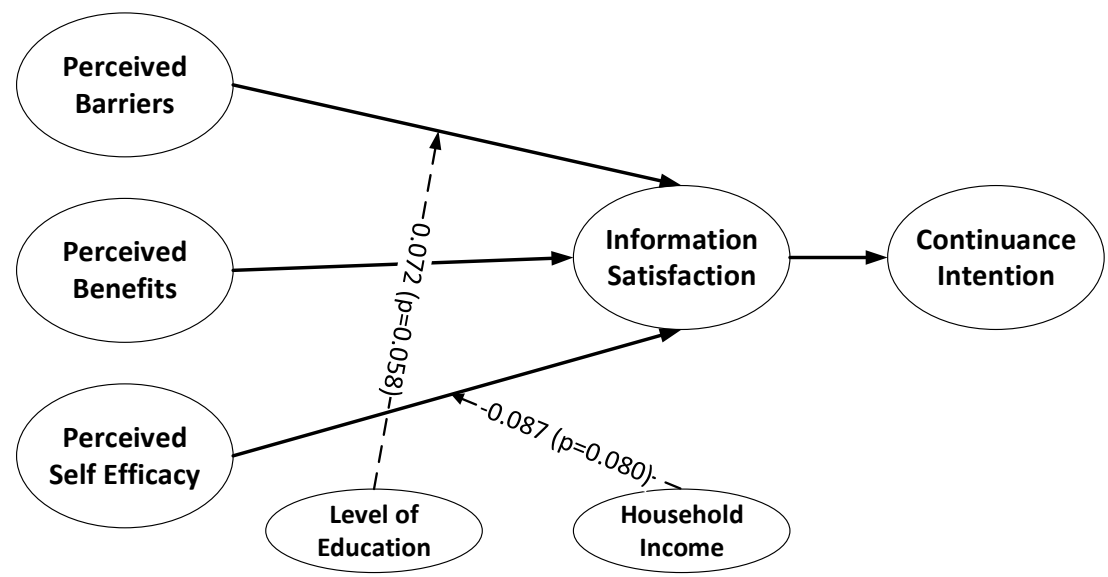

Figure 2. Online Health Information Seeking Behaviour Continuance Model

Table 2. Results of Path Analysis of the Proposed Model using Partial Least Square (PLS)

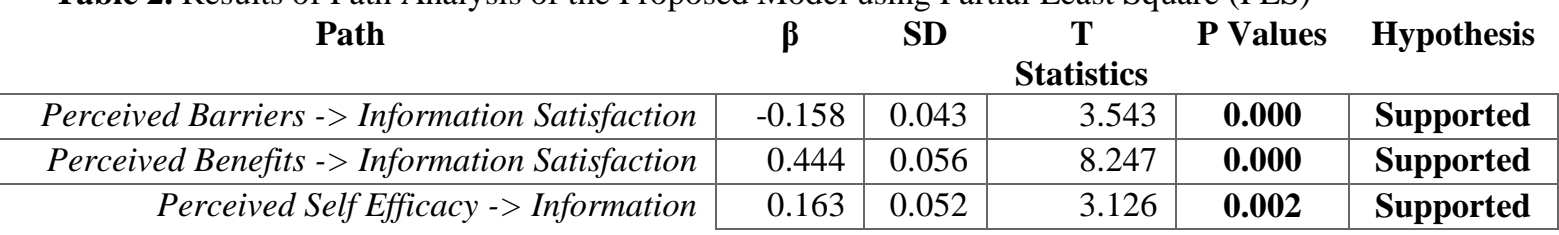


Factors Affecting Continued Use of Online Health Information Seeking Behaviour Among Parents in Developing Countries

\begin{tabular}{|r|r|r|r|r|r|}
\hline Satisfaction & & & & & \\
\hline $\begin{array}{r}\text { Information Satisfaction -> Continuance } \\
\text { Intention }\end{array}$ & 0.256 & 0.063 & 4.074 & $\mathbf{0 . 0 0 0}$ & Supported \\
\cline { 2 - 6 }
\end{tabular}

Table 3. Results of Moderating Effects on the Proposed Model

\begin{tabular}{cc|c|c|c|} 
Moderating Effect & $\boldsymbol{\beta}$ & \multicolumn{2}{c}{ SD } & \multicolumn{2}{c}{ T } & P Values \\
\hline Perceived Barriers -> Education -> Information Satisfaction & 0.070 & 0.038 & 1.894 & $0.058^{*}$ \\
\hline Perceived Self Efficacy -> H Income -> Information Satisfaction & -0.086 & 0.049 & 1.750 & $0.080^{*}$ \\
\hline
\end{tabular}

\section{Conclusion}

This paper finds that parents' satisfaction on online health information significantly influences continuance intention. While the perceived benefits, perceived barriers, and perceived self-efficacy influence satisfaction.

The paper has also attempted to explain the moderating effect of gender, level of education and household income on the variables on perceptions towards the information satisfaction. The results showed that household income negatively moderated the positive relationships between perceived self-efficacy and online health information satisfaction. On the other hand, education was found positively moderating the negative relationship between perceived barriers and information satisfaction. This means the higher the level of education of a parent, the negative relationship between perceived barriers and information satisfaction would diminish.

It is believed that the enhanced model would help policy makers to better understand the factors affecting online health information seeking behaviours among parents, and formulate appropriate intervention program.

\section{Acknowledgments}

The authors would like to express their gratitude to the Malaysian Ministry of Higher Education (MOHE), which has provided funding for the research through the Fundamental Research Grant Scheme, FRGS17-012-0578.

\section{References}

1. Internetworldstats, 2019. Internet Users Distribution in the World - Mid-Year 2019.

2. Escoffery, C., Miner, K.R., Adame, D.D., Butler, S., McCormick, L., and Mendell, E., 2005. Internet use for health information among college students Routledge, 183-188. DOI= http://dx.doi.org/10.3200/JACH.53.4.183-188.

3. Jacobs, W., Amuta, A.O., and Jeon, K.C., 2017. Health information seeking in the digital age: An analysis of health information seeking behavior among US adults. Cogent Social Sciences 3, 1. DOI= http://dx.doi.org/10.1080/23311886.2017.1302785.

4. Altin, S.V. and Stock, S., 2016. The impact of health literacy, patient-centered communication and shared decision-making on patients' satisfaction with care received in German primary care practices. BMC Health Services Research 16, 1. DOI= http://dx.doi.org/10.1186/s12913-016-1693-y.

5. Simou, E., 2015. Health information sources: trust and satisfaction. IJH 2, 1, 38-43.

6. Wu, B., 2018. Patient continued use of online health care communities: web mining of patient-doctor communication. Journal of medical Internet research 20, 4, e126.

7. Lee, S.Y., Hwang, H., Hawkins, R., and Pingree, S., 2008. Interplay of negative emotion and health self-efficacy on the use of health information and its outcomes. Communication Research 35, 3, 358381. DOI= http://dx.doi.org/10.1177/0093650208315962.

8. Nicholl, H., Tracey, C., Begley, T., King, C., and Lynch, A.M., 2017. Internet use by parents of children with rare conditions: findings from a study on parents' web information needs. Journal of medical Internet research 19, 2, e51.

9. Gage, E.A. and Panagakis, C., 2012. The devil you know: parents seeking information online for paediatric cancer. Sociology of Health \& Illness 34, 3 (2012/03/01), 444-458. DOI= http://dx.doi.org/10.1111/j.1467-9566.2011.01386.x.

10. Khoo, K., Bolt, P., Babl, F.E., Jury, S., and Goldman, R.D., 2008. Health information seeking by parents in the Internet age. Journal of paediatrics and child health 44, 7-8, 419-423.

11. Jaks, R., Baumann, I., Juvalta, S., and Dratva, J., 2019. Parental digital health information seeking behavior in Switzerland: A cross-sectional study. BMC Public Health 19, 1. DOI= http://dx.doi.org/10.1186/s12889-019-6524-8. 
12. Moon, R.Y., Mathews, A., Oden, R., and Carlin, R., 2019. Mothers' Perceptions of the Internet and Social Media as Sources of Parenting and Health Information: Qualitative Study. J Med Internet Res 21, 7 (Jul 9), e14289. DOI= http://dx.doi.org/10.2196/14289.

13. Hsiao, C.-H., Chang, J.-J., and Tang, K.-Y., 2016. Exploring the influential factors in continuance usage of mobile social Apps: Satisfaction, habit, and customer value perspectives. Telematics and Informatics 33, 2, 342-355.

14. Bhattacherjee, A., 2001. Understanding Information Systems Continuance: An ExpectationConfirmation Model. MIS Quarterly 25, 3, 351-370. DOI= http://dx.doi.org/10.2307/3250921.

15. Pluye, P., El Sherif, R., Granikov, V., Hong, Q.N., Vedel, I., Galvao, M.C.B., Frati, F.E.Y., Desroches, S., Repchinsky, C., Rihoux, B., Légaré, F., Burnand, B., Bujold, M., and Grad, R., 2019. Health outcomes of online consumer health information: A systematic mixed studies review with framework synthesis John Wiley and Sons Inc., 643-659. DOI= http://dx.doi.org/10.1002/asi.24178.

16. Hiebert, B., Leipert, B., Regan, S., and Burkell, J., 2018. Rural men's health, health information seeking, and gender identities: A conceptual theoretical review of the literature. American journal of men's health 12, 4, 863-876.

17. Malaysia Communications and Multimedia Comission (MCMC), 2018. Internet Users Survey 2018: Statistical Brief Number Twenty-Three.

18. Henseler, J., Ringle, C.M., and Sarstedt, M., 2015. A new criterion for assessing discriminant validity in variance-based structural equation modeling. Journal of the academy of marketing science 43, 1, 115135.

19. Wright, R.T., Campbell, D.E., Thatcher, J.B., and Roberts, N., 2012. Operationalizing multidimensional constructs in structural equation modeling: Recommendations for IS research. Communications of the Association for Information Systems 30, 1, 23.

20. Chin, W., 2000. Partial least squares for IS researchers: an overview and presentation of recent advances using the PLS approach. In ICIS, 741-742.

21. Ajaegbu, O. O., \&Ubochi, I. I. 2016. Health Seeking Behaviour among Undergraduates in the Faculty of Health Sciences and Technology, University of Nigeria Enugu Campus. International Journal of Evaluation and Research in Education, 5(3), 181-188.

22. Tuluk, G., \&Kepceoglu, I. 2019. Pre-Service Teachers' Web Pedagogical Content Knowledge and Online Information Searching Strategies. International Journal of Evaluation and Research in Education, 8(2), 229-236.

23. Vaghefi, I., \& Tulu, B. 2019. The continued use of mobile health apps: insights from a longitudinal study. JMIR mHealth and uHealth, 7(8), e12983.

24. Manierre, M. J. 2015. Gaps in knowledge: tracking and explaining gender differences in health information seeking. Social Science \& Medicine, 128, 151-158.

25. Park, H., \& Park, M. S. 2014. Cancer information-seeking behaviors and information needs among Korean Americans in the online community. Journal of community health, 39(2), 213-220. 